\title{
The Reliability of the Reversed Flow Posterior Interosseous Flap for the Coverage of Ulnar Hand Defects: A Series of 25 Cases
}

\author{
Yasser Abdallah Aboelatta, Ibrahim Husseine Kamel, Mohammed Abdelmohsen \\ Ghanem, Khaled Ahmad Reyad and Ayman Abulmakarem Shaker
}

Plastic Surgery Department, Faculty of Medicine, Ain -Shams University, Cairo, Egypt

Correspondence should be addressed to: Yasser Abdallah Aboelatta; dr_yaser72@hotmail.com

Received Date: 8 December 2013; Accepted Date: 25 February 2014; Published Date: 31 May 2014

Academic Editor: Yakup Çil

Copyright (C) 2014 Yasser Abdallah Aboelatta, Ibrahim Husseine Kamel, Mohammed Abdelmohsen Ghanem, Khaled Ahmad Reyad and Ayman Abulmakarem Shaker. Distributed under Creative Commons CC-BY 3.0

\begin{abstract}
The reversed radial forearm flap is considered the workhorse flap for hand reconstruction, while the posterior interosseous artery (PIA) flap did not take the same interest. This paper presents 25 cases with ulnar side hand defects that was reconstructed with PIA flap with 22 flaps survived (88\%). The PIA flap seems a good option and should be considered as another option for hand coverage when the surgeon prefers not to use free tissue transfer or the radial artery flap. The flap should be learned to senior and junior reconstructive surgeons, because familiarity with the flap anatomy lessens the operative time greatly and makes surgical dissection easier.
\end{abstract}

Keywords: Hand defect, reconstruction, posterior interosseous flap.

\section{Introduction}

The reverse posterior interosseous flap was first reported in 1986 by Lu et al [1] and Penteado et al [2]. Although, any upper extremity defect could be solved with either a distant pedicled flap or a free tissue transfer, the regional flaps from the forearm are considered the better options. The merits of a regional flap are single stage elevation, avoidance of hand dependency, early mobilization, and restriction of deformity to ipsilateral extremity [3].

The posterior interosseous artery (PIA) flap provides thin, soft and pliable skin with good colour and texture match. It has traditionally been used to cover defects up to the metacarpophalangeal joint and for reconstruction of the first web space. However, some authors have reported a high incidence of complications, particularly venous congestion with partial or total flap loss [4].

The current study reports our experience with the use of reversed PIA flap for coverage of ulnar aspect defects of the hand in a series of 25 patients. The technical difficulties, outcome, and complications rate are presented.

Cite this Article as: Yasser Abdallah Aboelatta, Ibrahim Husseine Kamel, Mohammed Abdelmohsen Ghanem, Khaled Ahmad Reyad and Ayman Abulmakarem Shaker (2014), "The Reliability of the Reversed Flow Posterior Interosseous Flap for the Coverage of Ulnar Hand Defects: A Series of 25 Cases," Plastic Surgery: An International Journal Vol. 2014 (2014), Article ID 171625, DOI: 10.5171/2014.171625 


\section{Materials and Methods}

This prospective study was conducted on 25 patients presented to causality department at Ain Shams University Hospitals over a period of 4 years. These patients were complaining of defects over the ulnar aspect of the hand with exposure of bones or tendons necessitating flap coverage. Patients with associated wrist injuries that would preclude the use of this flap were excluded. In addition, patients with systemic diseases as diabetes, ischemic heart disease, atherosclerosis, and vascular diseases were excluded from the study to avoid the possibility of peripheral vascular diseases and their effect on the blood flow to the flap.

Complete history and physical examination were taken at the plastic surgery department. Allen's test was done preoperatively to detect the dominant artery in case of failure of harvesting the posterior interosseous artery flap; Radial forearm flap was the next option. Preoperative plain X-ray hands (anteroposterior, oblique lateral views) were obtained. Preoperative colour duplex device was performed for assessment of the blood flow in the posterior interosseous artery was done for all patients.

\section{Surgical Anatomy}

The course of the posterior interosseous artery was marked following a line drawn between the lateral epicondyle of the humerus to the ulnar styloid process. It arises at a point 4-6 cm distal to the lateral epicondyle, usually as a branch of the common interosseous artery but on occasion directly from the ulnar artery ${ }^{2}$. At the level of the proximal third of the forearm, the PIA runs with the posterior interosseous nerve (PIN), and gives off several well-defined septocutaneous perforators to the dorsal aspect of the forearm. The first proximal cutaneous branch is a large skin perforator with a variable origin that courses in the intermuscular septum to supply the subcutaneous tissue overlying the proximal third of the dorsal forearm [5].
In the distal third of the forearm, the PIA gives off several perforators (6-8) which supply the skin together. Upon approaching the level of the wrist joint, $2 \mathrm{~cm}$ proximal to the distal radio-ulnar joint, the PIA anastomose with the dorsal recurrent branch of the anterior interosseous artery (AIA). Normal physiologic blood flow to the distal third of the forearm comes from this distal anastomosis, and not from the proximal PIA. This vascular arcade allows the PIA flap to be used as a reverse pedicled flap when the PIA is divided proximally. The reversed flow posterior interosseous artery flap is drained by the venae comitantes accompanying the feeding artery to the deep venous system with no superficial system drainage [6].

The PIA has a relatively narrow calibre in the middle third where also the anatomical variances are reported to be the most. Problems are encountered while trying to reach the most distant defects of the first web space, distal amputation defects, the radial, palmar areas and distal to PIP joints. More variations are met during dissection proximal to the distal third of the forearm [7].

\section{Operative Technique}

All surgical procedures were performed under general anaesthesia and tourniquet and by the same surgical team. Wound debridement including soft tissues and bones was undertaken till a healthy bed was reached for flap inset.

The reversed flow PIA flap was raised either from proximal, middle or distal one thirds of the forearm according to the size of the defect and the distal reach of the flap. Flap elevation started with dissection of the pedicle in the distal forearm (area of anastomosis between the posterior interosseous and the anterior interosseous artery arteries) to exclude any possibility of deficient anastomosis.

Two skin incisions were made on both sides of the marked course of the artery leaving about one $\mathrm{cm}$ skin bridge inbetween. This skin bridge changed the shape of the island flap into a racquet 
shaped flap as described in a previous work [8]. The plane of dissection is between the skin and the ante-brachial fascia. Then, the fascia over the tendons of the tendons of the extensor digitorum communis (EDC) and extensor carpi ulnaris (ECU) was incised. The PIA could be observed coursing along the intermuscular septum between the extensor digiti quinti (EDQ) and the ECU. At the pivot point, the anastomosis arc was observed to ensure its existence.

Then, the radial edge of the flap was incised into the EDC. Dissection was continued on ulnar aspect towards the intermuscular septum between the EDQ and ECU. During the dissection, the fascia to the skin paddle is secured with interrupted sutures. Then, the ulnar edge was incised and dissected radially towards the septum, also along the plane between the fascia and the muscle.

The intermuscular septum between the EDQ and ECU is the landmark of dissection, along which the PIA and its venae comitantes course distally. After completing the dissection of the PIN, the intermuscular septum was detached from the ulna. The pedicle of the flap consisted of the PIA, venae comitantes and intermuscular septum between the EDQ and ECU. Finally the origin of the PIA was ligated and completes the harvest of the flap.

\section{Results}

This study included 25 patients (23 males and 2 females) with ages ranging from 12 -
56 years with a mean of 25 years. The most affected age group was 20-30 years (74\%). Flap harvest time ranged 70- 90 minutes and total operative time ranged from 2-2.5 hours.

The size of the defects ranged from $3 \times 4$ $5 \times 7 \mathrm{~cm}$ on the ulnar side of the hand with mean of $4.08 \pm 0.81 \times 5.6 \pm 1 \mathrm{~cm}$ with exposed bones or tendons. The posterior interosseous artery was found with efficient anastomosis and blood flow in all cases.

Regarding flap course and survival; 20 flaps (80\%) passed uneventful, 4 flaps (16\%) suffered from venous congestion, and one flap (4\%) showed ischemia. Three flaps (the ischemic flap and 2 congested flaps) suffered total loss and required coverage using reversed flow radial forearm flap. The other 2 flaps survived without loss, so we had 22 survived flaps (88\%) (Figures $1 \& 2$ ). All the donor sites needed coverage by split thickness skin grafts. Other recorded complications were wound infection occurred in 3 patients $(12 \%)$ that resolved by conservative management and hematoma occurred in one case (4\%) and required early evacuation; it is of note that the flap survived in all these cases.

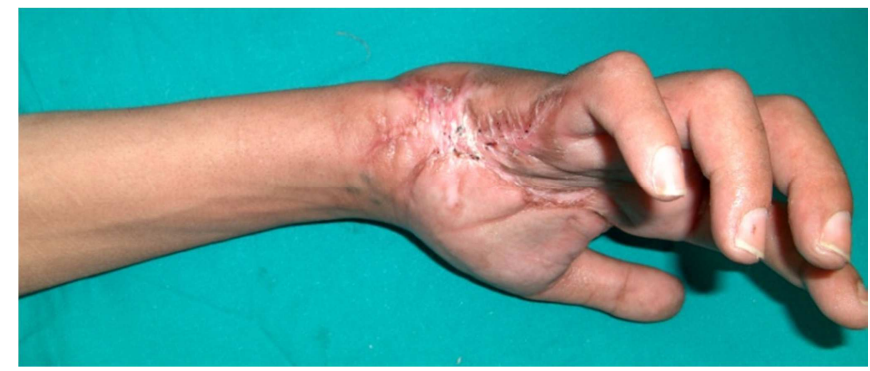

Figure 1a

Yasser Abdallah Aboelatta, Ibrahim Husseine Kamel, Mohammed Abdelmohsen Ghanem, Khaled Ahmad Reyad and Ayman Abulmakarem Shaker (2014), Plastic Surgery: An International Journal, DOI: 




Figure 1b

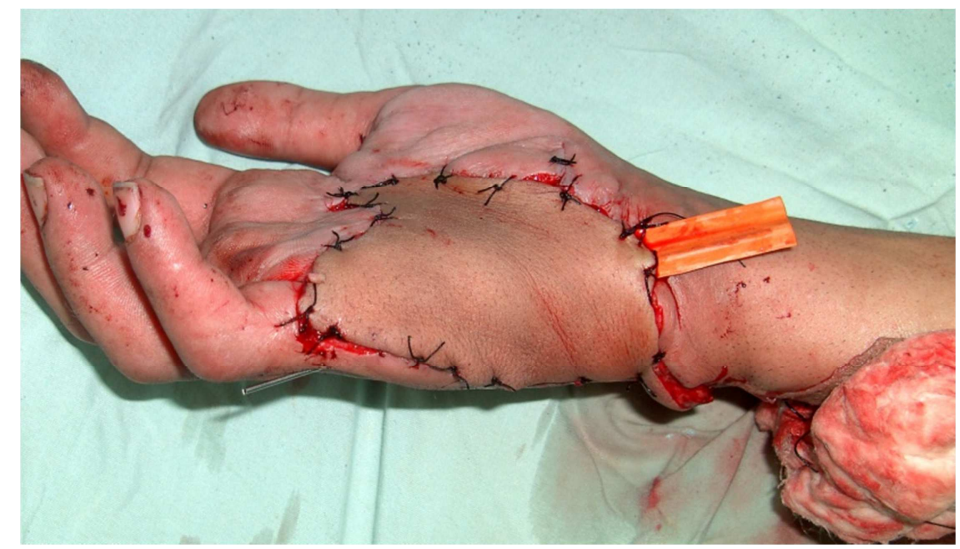

Figure 1c

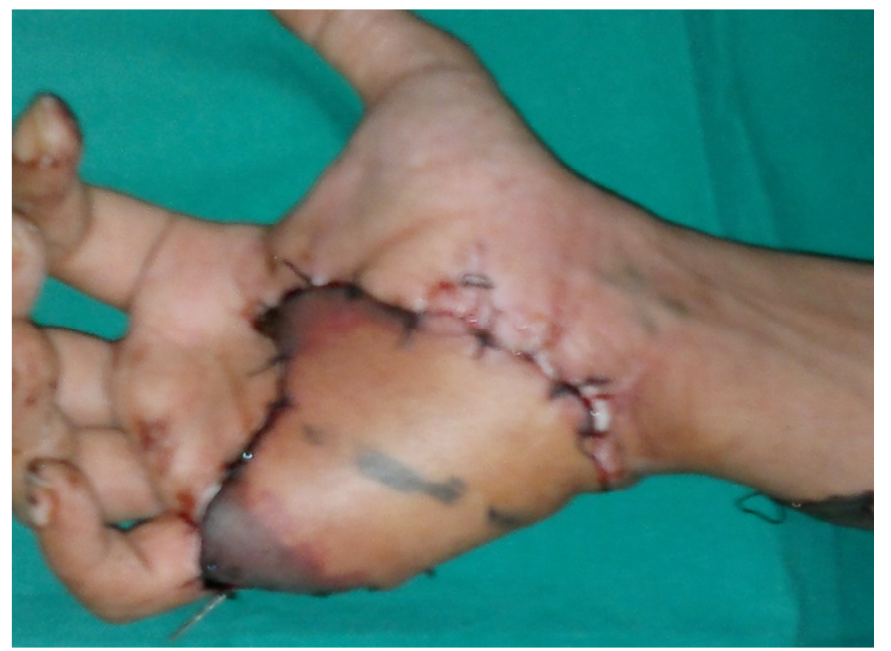

Figure 1d

Yasser Abdallah Aboelatta, Ibrahim Husseine Kamel, Mohammed Abdelmohsen Ghanem, Khaled Ahmad Reyad and Ayman Abulmakarem Shaker (2014), Plastic Surgery: An International Journal, DOI: 


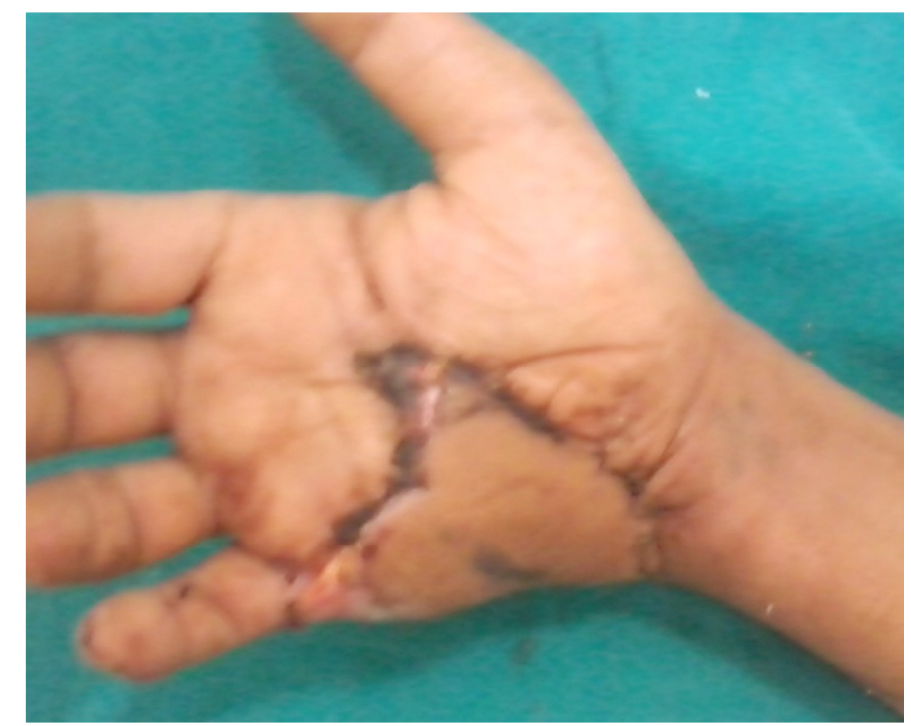

Figure 1e

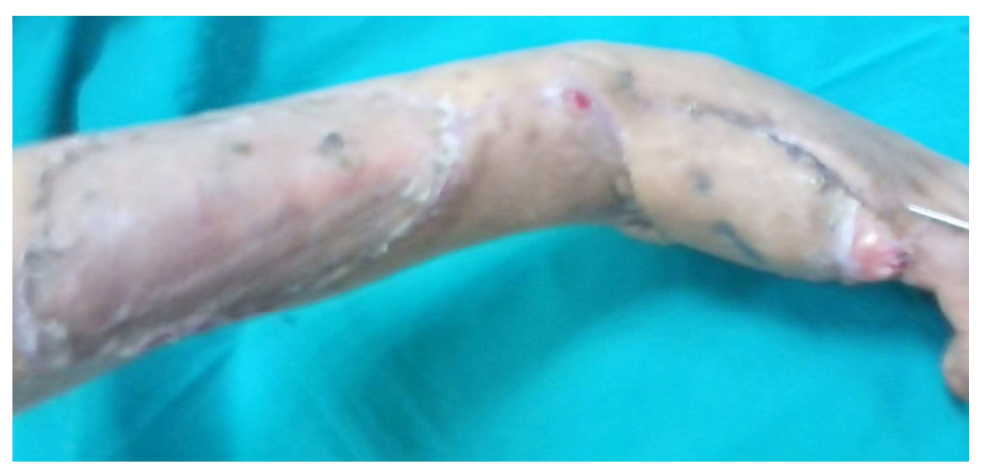

Figure 1f

Figure 1: (a) A Preoperative Photo of a 26 Male Patient with Post Traumatic Ulnar Side Defect of the rt Hand, (b) Debridement of All Scarred Tissues was Done, (c) the Flap is Harvested and Inset, (d) 2 Weeks Postoperative View Showing Distal Edge Necrosis, (e \&f) 2 Moths Postoperative Views

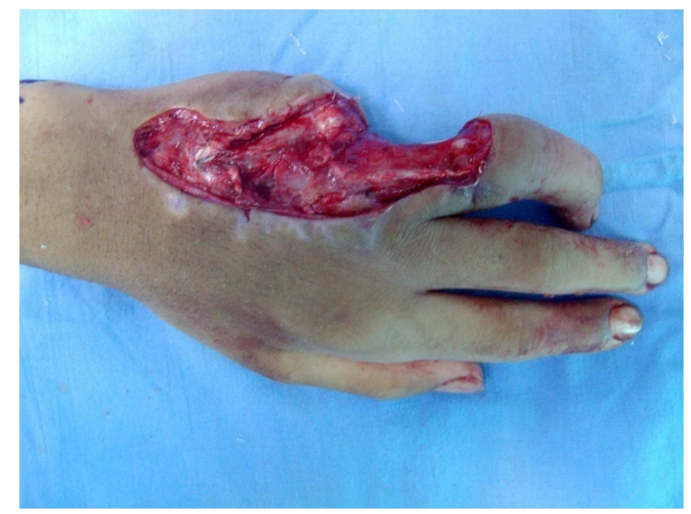

Figure 2a 




Figure 2b

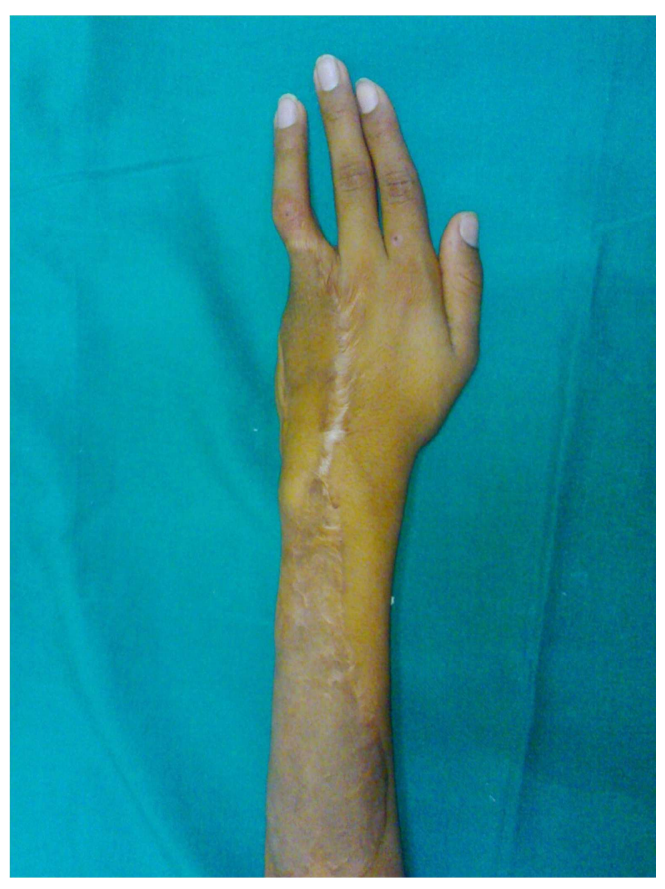

Figure 2c 


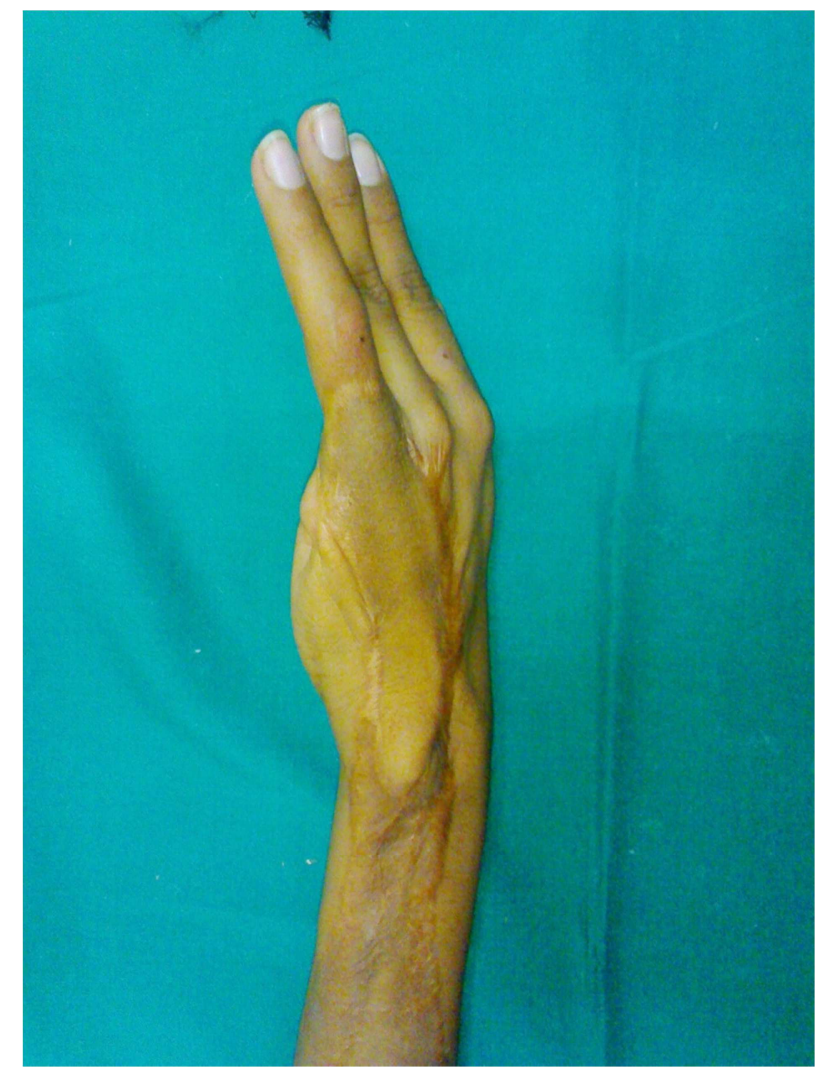

Figure 2d

Figure 2: (a) 12yrs Old Male with PT Raw Area over the Ulnar Aspect of the Lt Hand with Amputated Little Finger at the Level of the MPJ He Underwent Two Debridement Operation then Coverage by PIA Flap, (b) 2 Weeks Postoperative View, (c \&d) 6 Months Antero-Posterior and Lateral Views Postoperative.

\section{Discussion}

Despite several flaps introduced for hand reconstruction, the reversed radial forearm flap is still largely preferred for hand reconstruction [9]. It is considered a workhorse flap in hand reconstruction [10]. It offers many merits such as adequately large, thin and pliable and colour matched tissues. It offers a simple and effective one-stage method of soft tissue reconstruction. Surgery is confined to a single site and limb permitting early mobilization and rehabilitation. Moreover, vascularized bone and tendon transfer, along with the flap, are possible. If the flap pedicle was designed with proper length, it could also cover the fingers [11-15].

On the other hand, the radial forearm flap that has many disadvantages has been reported such as poor donor sit skin graft take, noticeable donor scar, bulky volar skin compared to thin dorsal skin, , hand swelling, reduced joint movement and strength, reduced sensation, coldintolerance, and radius fracture[16] [17]. Moreover, acute ischemia of the hand has been reported in spite of adequate circulation by preoperative Allen's test [18]. In a review for the clinical trials to reduce donor site morbidity, Loeffelbein et al [19] concluded that, most publications failed to provide the solid evidence characteristic of high-quality research.

The reversed flow posterior interosseous artery flap (PIA) is a valuable option for reconstruction of hand defects. As it is based on the anterior-posterior interosseous artery system, it avoids sacrifice of either the radial or ulnar 
arteries as in case of the radial or ulnar forearm flaps. It is also possible to use this flap in circumstances where there has been damage to the palmer arch. In addition, the dorsal forearm skin is less bulky than the volar forearm skin; therefore, the PIA flap has better contour match. Furthermore, the donor site can often be closed primarily if the defect is small or by a skin graft, that will take well on the muscle bellies of the extensor carpi ulnaris and extensor digiti minimi [3]. Also in the event of flap failure, the PIA flap can be debrided and the defect skin grafted, while all other flap options remain available. This relative expendability of the PIA flap is one of its unique qualities [20]. Lastly, the flap can also be raised with a segment of the proximal third of the ulna as an osteocutaneous flap for bone defects, including thumb reconstruction [21].

In this study, 25 PIA flaps were harvested to close the ulnar side defects of the hand. The flap survival rates were comparable to other reported studies [22, 23] which supports its safety. Our results also showed a similar range of complications [23-28].

The flap can be considered as a smart and reliable option for coverage of the ulnar side of the hand, as it doesn't sacrifice the main arteries of the forearm and hand. It is a single stage procedure with no need for $2^{\text {nd }}$ stage division. It doesn't need special equipments or special training like microsurgical transfer.

The flap was harvested with a skin bridge over the pedicle changing the island flap into a racquet shaped flap as described in a previous work [8]. The racquet shape modification of the flap avoids compression of the vascular pedicle which can develop in case of tunneling under skin or skin direct closure. In addition, it allows easy flap inset, enhances venous drainage as this skin bridge contains additional subcutaneous venous plexus. The skin strip can be also used for solving any additional local skin problems.

Although the radial forearm flap has higher success rates than PIA flap, and has been considered the workhorse flap for hand reconstruction; it seems less satisfactory compared to PIA flap especially for ulnar side hand defects. The PIA flap seems to be a reliable option for reconstructing the ulnar side of the hand. We feel that the PIA must be considered as one of the new preferred valuable flaps for hand reconstruction. This flap must be learned well to both senior and junior staff and should be considered as another option for hand coverage when the surgeon prefers not to use free tissue transfer or the radial artery flap. Gentle pedicle dissection and avoidance of pedicle compression using the racquet shape design reduce flap necrosis. During flap elevation, we could harvest a skin paddle up to only 3-4 $\mathrm{cm}$ below the lateral epicondyle of the humerus that enabled us to cover defects down to the middle phalanges. In addition, anastomotic vessel dissection as described by Bayon and Pho ${ }^{4}$ also increases flap arc of rotation. In the last decade, the senior author (Ayman shaker) as well as the other authors used the posterior interosseous flap in more than 80 cases of hand and upper limb reconstruction and they believe that the PIAF can be used efficiently to solve many problematic defects.

\section{Conclusion}

The PIA flap seems a smart and reliable option for coverage of the ulnar side of the hand. Further evidence- base has shown that the PIA flap should be considered as a reliable choice in hand reconstruction especially ulnar side defects. The flap should be learned to senior and junior reconstructive surgeons as a classical flap for hand reconstruction. Familiarity with the flap anatomy lessens the operative time greatly and makes surgical dissection easier.

\section{References}

1. Lu, L. J., Wang, S. F., Yang, J. et al. (1986). 'The Posterior Interosseus Flap: A Report of 6 Cases,' The Second Symposium of the Chinese Association of Hand Surgery (Qing Dao city); 187e91.

2. Penteado, C. V., Masquelet, A. C. \& Chevrel, J. P. (1986). 'The Anatomic Basis of the Fasciocutaneous Flap of 
the Posterior Interosseus Artery,' Surg Radiol Anat; 8: 209e15.

3. Zancolli, E. A. \& Angrigiani, C. (1988). "Posterior Interosseous Island Forearm Flap," Journal of Hand Surgery: British \& European Volume; 13-B: $130 \mathrm{e} 5$.

4. Bayon, P. \& Pho, R. W. H. (1988). "Anatomical Basis of Forearm Flap Based on Posterior Interosseus Vessels," Journal of Hand Surgery 13B: 435.

5. Giunta, R. E. \& Lukas, B. (1998). "Impossible Harvest of the Posterior Interosseus Artery Flap: A Report of an Individualised Salvage Procedure," British Journal of Plastic Surgery 51: 642-645.

6. Costa, H. \& Soutar, D. S. (1988). "The Distally Based Island Posterior Interosseus Flap," British Journal of Plastic Surgery 41: 221-217.

7. Brunelli, F., Giele, H. \& Perrotta, R. (2000). "Reverse Posterior Interosseus Flap Based on an Exteriorized Pedicle to Cover Digital Skin Defects," Journal of Hand Surgery British; 25: 296-9.

8. Nasser, S., Abdallah, Y. \& Shaker, A. A. 2011). "Racquet-Shaped Modification of the Island Pedicle Flaps: A Simple Design to Increase its Versatility and to Decrease the Complication Rate, Egypt," Egyptian Journal of Plastic and Reconstructive Surgery, Vol. 35, No. 1, January: 31-40.

9. Megerle, K., Sauerbier, M. \& Germann, G. (2010). "The Evolution of the Pedicled Radial Forearm Flap," Hand; 5(1): 37-42.

10. Friedrich, J. B. \& Pederson, W. C., Bishop, A. T., Galaviz, P. \& Chang, J. (2012). "New Workhorse Flaps in Hand Reconstruction," Hand 7:45-54.

11. Soutar, D. S. \& Tanner, N. S. B. (1984). "The Radial Forearm Flap in the
Management of Soft Tissue Injuries of the Hand," British Journal of Plastic Surgery, Volume 37, Issue 1, 18-26.

12. Jones, N. F., Jarrahy, R. \& Kaufman, M. R. (2008). "Pedicled and Free Radial Forearm Flaps for Reconstruction of the Elbow, Wrist, and Hand," Plastic \& Reconstructive Surgery; 121(3): 88798.

13. Taghinia, A. H., Carty, M. \& Upton, J. (2010). "Fascial Flaps for Hand Reconstruction," Journal of Hand Surgery; 35(8): 1351-5.

14. Kim, K. S., Kim, E. S., Hwang, J. H. \& Lee, S. Y. (2010). "Thumb Reconstruction Using the Radial Midpalmar (Perforator Based) Island Flap (Distal Thenar Perforator-Based Island Flap)," Plastic \& Reconstructive Surgery; 125(2): 601-8.

15. El-Khatib, H. A. \& Hammouda, A. H. (2005). "Reverse Osseofasciocutaneous Radial Forearm Flap for Thumb Reconstruction: A Flap Design and Case Series," Journal of Hand Surgery; 30(6): 1298-304.

16. Page, R. \& Chang, J. (2006). "Reconstruction of Hand Soft-Tissue Defects: Alternatives to the Radial Forearm Fasciocutaneous Flap," Journal of Hand Surgery, 31(5): 84756.

17. Timmons, M. J., Missotten, F. E. M., Poole, M. D. \& Davies, D. M. (1986). "Complications of Radial Forearm Flap Donor Sites," British Journal of Plastic Surgery, Volume 39, Issue 2: 176-178.

18. Jones, B. M. \& O'Brien, C. J. (1985). "Acute Ischaemia of the Hand Resulting from Elevation of a Radial Forearm Flap," British Journal of Plastic Surgery, Volume 38, Issue 3: 396-397.

19. Loeffelbein, D. J., Al-Benna, S. et al. (2012). "Reduction of Donor Site Morbidity of Free Radial Forearm Flaps: What Level of Evidence Is Available?," Eplasty; 12: e9.

Yasser Abdallah Aboelatta, Ibrahim Husseine Kamel, Mohammed Abdelmohsen Ghanem, Khaled Ahmad Reyad and Ayman Abulmakarem Shaker (2014), Plastic Surgery: An International Journal, DOI: 
20. Costa, H., Pinto, A. \& Zenha, H. (2007). 'The Posterior Interosseus Flap e a Prime Technique in Hand Reconstruction,' The Experience of 100 Anatomical Dissections and 102 Clinical Cases; PRS March.

21. Hsu, C. \& Chang, J. (2003). "The Posterior Interosseus Artery Flap Revisited," Operative Techniques in Plastic and Reconstructive Surgery, Vol 9, No 4: p 173-180.

22. Fujiwara, M., Kawakatsu, M., Yoshida, Y. \& Sumiya, A. (2003). "Modified Posterior Interosseus Flap in Hand Reconstruction," Techniques in Hand and Upper Extremity Surgery, 7 (3): 102-109.

23. Balakrishnan, G., Kumar, B. S. \& Hussein, S. A. (2003). "Reverse Flow Posterior Interosseus Artery Flap Revisited," Plastic \& Reconstructive Surgery, 111 (7): 2364-2369.

24. Shibata, M., Iwabuchi, Y., Kubota, S. et al. (1997). "Comparison of Free and Reversed Pedicled Posterior Interosseus Flap," Plastic \& Reconstructive Surgery, 99: 791-802.
25. Buchler, U. \& Frey, H.- P. (1991). "Retrograde Posterior Interosseus Flap," Journal of Hand Surgery [Am.], 16A: 283-292.

26. Dap, F., Dautel, G., Voche, P. et al. (1993). "The Posterior Interosseus Flap in Primary Repair of Hand Injuries," Journal of Hand Surgery. (Br.), 18 (4): 437-45.

27. Brunelli, F., Valenti, P., Dumonitier, C. et al. (2001). "The Posterior Interosseus Reverse Flap: Experience with 113 Flaps," Annals of Plastic Surgery, 47: 25-30.

28. Koch, H., Kursumovic, A., Hubmer, M. et al. (2003). "Defects on the Dorsum of the Hand - The Posterior Interosseus Flap and its Alternatives," Journal of Hand Surgery, 8: 205-12. 